\title{
REKAYASA ALAT MESIN CASTING UNTUK PERAJIN PEWTER
}

\author{
Suminto
}

\begin{abstract}
The total production of tin from PT. Timah in 2014 by 32.319 ton. At this time, most of tin mines production still exported in form of bullion, the rest in form chemical tin and solder. To provide added value then it can be made into products, one of them is the craft of pewter. Pewter is a white colored metal alloy like britanium metal or commonly called pewter with the largest metal content is combined with small part of antimony or copper or both.

Technology that used in the craft of pewter still using a simple casting technology i.e. using a casting tecnique by gravity. So the production capacity is still low. These researches are engineering and exploiting the casting machine to increase production capacity. The result obtained are castingmachine with specifications dimension $50 \mathrm{~cm} \times 50 \mathrm{~cm} \times 50 \mathrm{~cm}$, electric motor DC 24 volt, power 250 watt, maximum rounds $360 \mathrm{rpm}$, disc diameter $29 \mathrm{~cm}$, production capacity 810 product/day.
\end{abstract}

Keywords: tin, casting machine, pewter craft, production capacity

\section{ABSTRAK}

Total produksi timah dari PT. Timah pada tahun 2014 sebesar 32.319 ton. Pada saat ini, sebagian besar hasil tambang timah masih di ekspor dalam bentuk batangan selebihnya dalam bentuk chemical tin dan solder. Untuk memberikan nilai tambah maka dapat dibuat produk, salah satunya adalah kerajinan pewter. Pewter adalah logam paduan berwarna putih seperti logam brittania atau biasa disebut pewter dengan kandungan logam terbesar adalah timah yang dipadu dengan sebagian kecil antimon atau tembaga atau keduanya.

Teknologi yang digunakan pada kerajinan pewter pada umumnya masih menggunakan teknologi casting yang sederhana yaitu menggunakan teknik casting secara gravitasi. Sehingga kapasitas produksinya masih rendah. Penelitian ini adalah merekayasa dan memanfaatkan mesin casting untuk meningkatkan kapasitas produksi. Hasil yang didapatkan adalah mesin casting dengan spesifikasi dimensi $50 \mathrm{~cm} \times 50 \mathrm{~cm} \times 50 \mathrm{~cm}$, motor listrik DC 24 volt, daya 250 watt, putaran maksimal $360 \mathrm{rpm}$, diameter cakram $29 \mathrm{~cm}$, kapasitas produksi 810 produk/hari.

Kata kunci : timah, mesin casting, kerajinan pewter, kapasitas produksi

\section{LATAR BELAKANG}

Saat ini teknologi produksi unit produksi kerajinan pewter sudah mengenal proses casting, namun masih kurang mampu untuk mengejar kapasitas produksi, dikarenakan mereka masih menggunakan sistem manual yaitu satu cetakan untuk satu produk, sehingga kecepatan dan kualitas produksinya masih rendah dan 
produk yang dihasilkan masih tebal tidak seperti aslinya

Melihat permasalahan tersebut di atas, perlu adanya inovasi alih teknologi yaitu rekayasa mesin casting sebagai pengganti casting cara manual.

\section{TINJAUAN PUSTAKA}

\section{Pengertian Cor (casting)}

Mengecor sama dengan menuang yaitu mencurahkan bahan dan benda cair ke dalam bejana atau rongga tertentu. Sifat dari zat cair adalah dapat mengalir mengisi ruang ke mana saja ke arah yang lebih rendah.

Pada buku Pengetahuan teknologi Kerajinan Logam 2 disebutkan bahwa pemberian bentuk logam dengan cara menuang logam cair ke dalam bejana atau rongga berbentuk tertentu dan kemudian dibiarkan sampai membeku dinamakan penuangan atau pengecoran .( Suwardo dan Bandono, 1980:3)

Dalam buku Tehnik Pengecoran Logam disebutkan bahwa coran dibuat dari logam yang dicairkan, dituang ke dalam cetakan, kemudian dibiarkan mendingin dan membeku.(Sudia, 1986:1). Pengecoran logam adalah membentuk produk dari logam yang telah dicairkan kemudian dituang dalam cetakan, dibiarkan dingin dan membeku. Hasilnya sesuai dengan rongga cetakan (model), sedangkan sifatsifat yang ada pada logam tidak berubah

\section{a. Penuangan biasa}

Penuangan biasa dilakukan dengan cara menuangkan cairan ke dalam cetakan melalui lubang penuangan. Bila logam dalam keadaan cair sekali, maka cairan mudah memenuhi rongga sampai ke bagian yang sempit. Tetapi apabila logam tersebut kental, maka cairan akan sulit mengalir ke dalam rongga-rongga yang sempit sehingga hasil pengecoran kurang baik.

$\begin{array}{llr} & \text { Penuangan ini sangat sederhana } \\ \text { sehingga pelaksanaannya tidak }\end{array}$ memerlukan peralatan yang mahal, karena itu sebagian besar penuangan logam dikerjakan dengan sistem ini. Sistem ini pula, para perajin dapat melaksanakan pekerjaan penuangan logam walaupun modalnya hanya sedikit. Beberapa kekurangan penuangan biasa adalah:

1. Produktivitas rendah karena dikerjakan dengan tenaga manusia

2. Cara ini sulit diterapkan untuk membuat benda-benda yang tipis.

\section{b. Pengecoran sentrifugal}

Pengecoran sentrifugal adalah suatu cara pengecoran dimana cetakan diputar dan logam cair dituangkan ke dalamnya, sehingga logam cair tertekan oleh gaya sentrifugal dan kemudian membeku.

Penuangan sentrifugal dilakukan dengan cara menuangkan logam cair ke dalam cetakan yang berputar dalam sikap mendatar. Dengan pengaturan putaran serta penuangan yang sesuai, maka logam akan tercetak secara halus dengan tebal yang sama. Beberapa keuntungan sistem penuangan sentrifugal yaitu:

1. Pengerjaan lebih cepat

2. Dapat digunakan untuk desain yang rumit dan tipis.

\section{Pewter}

Pewter adalah logam paduan berwarna putih seperti logam brittania atau biasa disebut pewter dengan kandungan logam terbesar adalah timah 
yang dipadu dengan sebagian kecil antimon atau tembaga atau keduanya. Logam paduan tersebut, proporsi timah berkisar dari sekitar $85 \%$ hingga $99 \%$ berat. Proporsi antimon berkisar hingga 15\%, dan proporsi tembaga hingga 15\%. Kombinasi antimon dan tembaga sering digunakan, tidak melebihi total sekitar $15 \%$, atau bahkan sejumlah $1 \%$, dengan sisanya adalah timah (Konigsberg, 1932). Pewter modern terdiri 90 sampai $98 \%$ timah, 1 sampai $8 \%$ antimon dan 0,25 sampai $3 \%$ tembaga (Graham, 1995).

\section{a. Kerajinan pewter}

Menurut Dessuy, (2011) timah sebagai logam tanpa paduan merupakan logam yang lunak jika digunakan sebagai peralatan dapur (kitchenware), tableware, dan cangkir minuman. Sehingga untuk memperbaiki sifatnya perlu penambahan logam lain seperti tembaga, bismuth, antimon dan timbal sebagai bahan tambahannya Selain produk diatas, logam pewter juga digunakan sebagai gantungan kunci, miniatur, plakat, dan lain-lain seperti yang ada di perajin Pewter

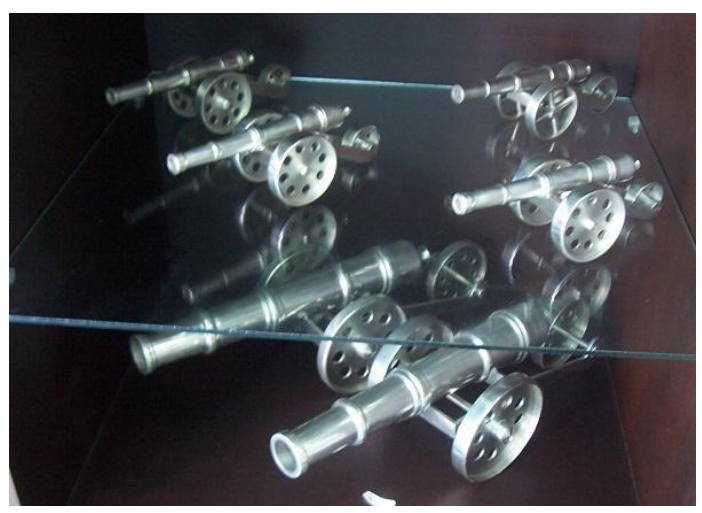

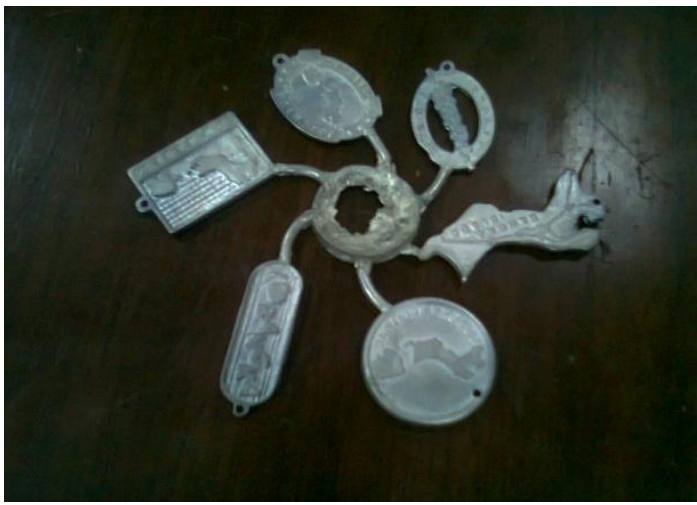

Gambar 1. Produk kerajinan pewter

\section{Mesin}

\section{Mesin casting}

casting sangat luas digunakan dalam proses prototyping industri sesbagai secondary process (Huan dan Jordaan, 2002). Mesin spin casting adalah mesin cetak logam dengan menggunakan gaya sentrifugal yang dibutuhkan untuk melempar logam cair pada sebuah karet cetakan.

\section{METODE PENELITIAN}

\section{A. BAHAN BAKU CASTING}

1. Pattern / Master / Pola Casting pada sebuah pattern/master/pola adalah replika dari objek yang akan digandakan, digunakan untuk menyiapkan rongga di mana bahan cair (logam) akan dituangkan dalam proses pengecoran. Pola yang dipakai dalam pengecoran pasir dapat terbuat dari kayu, logam, plastik atau bahan lainnya. Pola dibuat untuk menuntut standar konstruksi, sehingga mereka bisa bertahan untuk jangka waktu yang wajar, sesuai dengan kelas kualitas pola dibangun, dan supaya mereka akan memberikan dimensi repeatably diterima casting. Pembuatan pola, yang disebut patternmaking adalah proses pembuatan pattern dengan teknik 
tertentu dengan alat dan proses pembuatan pola. Patternmakers adalah seorang yang menguasai keterampilan baik yang didapat melalui magang dan sekolahsekolah selama bertahun-tahun dan berpengalaman. Namun dalam prakteknya terkadang seorang designer yang merancang pola, dan patternmaker yang mengeksekusi desain tersebut ke dalam bentuk pola. (sumber: http://www.en.wikipedia.org/wiki/Pattern)

\begin{tabular}{|c|l|}
\hline \multicolumn{2}{|c|}{ Physical properties } \\
\hline Phase & solid \\
\hline Density (near r.t.) & (white) $7.365 \mathrm{~g} \cdot \mathrm{cm}^{-3}$ \\
\hline Density (near r.t.) & (gray) $5.769 \mathrm{~g} \cdot \mathrm{cm}^{-3}$ \\
\hline $\begin{array}{c}\text { Liquid density at } \\
\text { m.p. }\end{array}$ & $6.99 \mathrm{~g} \cdot \mathrm{cm}^{-3}$ \\
\hline $\begin{array}{c}\text { Melting point } \\
\text { Boiling point }\end{array}$ & $\begin{array}{l}505.08 \mathrm{~K}, 231.93^{\circ} \mathrm{C} \\
449.47^{\circ} \mathrm{F}\end{array}$ \\
\hline Heat of fusion & $($ white $) 7.03 \mathrm{~kJ} \cdot \mathrm{mol}^{-1}$ \\
\hline Heat of vaporization & $\left(\right.$ white) $296.1 \mathrm{~kJ} \cdot \mathrm{mol}^{-1}$ \\
\hline $\begin{array}{c}\text { Specific heat } \\
\text { capacity }\end{array}$ & $\begin{array}{l}\left(25^{\circ} \mathrm{C}\right)(\mathrm{white}) 27.112 \\
\mathrm{~J} \cdot \mathrm{mol}{ }^{-1} \cdot \mathrm{K}^{-1}\end{array}$ \\
\hline
\end{tabular}

Tabel 1 Sifat fisik logam timah

Sumber: http://www.en.wikipedia.org/ wiki/Tin

\section{Metal/Logam}

Pewter adalah logam paduan (metal alloy) antara timah (Sn) dengan logam lain. Logam lain yang biasa ditambahkan adalah tembaga (Cu) dan antimony. Pada sejarahnya secara tradisional antara 85 dan 99 persen timah, dengan sisanya terdiri dari tembaga, antimony, bismut dan timbal. Tembaga dan antimony bertindak sebagai bahan yang memperbaiki kekerasan dari timah. Dalam kegiatan ini kami menggunakan bahan baku pewter dan dikombinasikan dengan timah hitam $(\mathrm{Pb})$ sebagai bahan tambahannya. Mengingat $\mathrm{Pb}$ juga masih satu golongan dengan Sn. Logam timah (Sn) mempunyai karakteristik sebagai berikut ini :

3. Moulding

Proses pengecoran spin casting biasanya menggunakan karet silikon atau organik sebagai bahan pembuatan cetakan. Vulkanisasi adalah langkah pemasakan karet yang terjadi di tengah-tengah proses pembuatan cetakan. Sebelum proses vulkanisasi, cetakan karet bersifat lembut, lentur dan padat. Proses vulkanisasi menyebabkan cetakan menjadi mudah dipotong dan dibentuk sesuai model yang disiapkan. Vulkanisasi ada dua tujuan, yang pertama membangun ruang negatif di dalam cetakan dan yang kedua untuk proses pengerasan karet sehingga akan tetap kuat dan kaku selama pengecoran. Setelah karet divulkanisasi, terlebih dahulu karet cetakan harus menjalani gating dan ventilasi.tujuannya membuat ukiran saluran untuk memastikan aliran udara dan bahan selama proses pengecoran. Membuat saluran gating biasanya dilakukan menggunakan pisau tajam atau pisau bedah. Pembuatan gating besarnya bervariasi tergantung pada kerumitan cetakan. Umur pakai atau kekuatan cetakan ini biasanya dapat bertahan hingga ratusan kali pengecoran. 


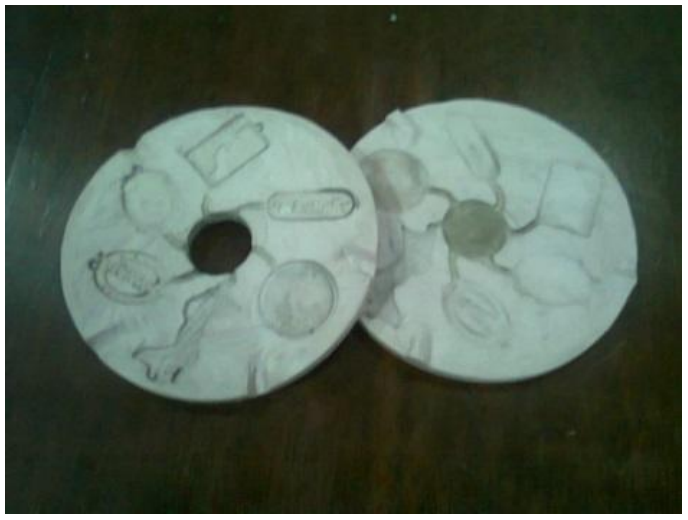

Gambar 2. Cetakan karet

\section{PERALATAN}

Dalam pekerjaan membuat kerajinan pewter dengan teknologi casting membutuhkan beberapa alat utama sebagai berikut ini :

1. Spin caster (mesin casting)

Sebuah mesin dengan prinsip kerja sebagai berikut, jika sebuah cakram atau disk diputar pada porosnya maka akan menimbulkan gaya sentrifugal ke luar. Jika sebuah benda cair dituangkan di tengahtengah cakram yang sedang berputar maka cairan tersebut akan terlempar keluar dengan gaya sentrifugal yang ada. Dengan prinsip kerja seperti diatas, maka jika sebuah karet cetakan (yang sudah ada bentuk negatif di dalamnya) diletakkan ditengah cakram tersebut dan diatasnya dituangkan benda cair maka benda cair itu akan terlempar keluar dan mengisi rongga negatif tersebut. Untuk waktu proses pengecoran selama 30-60 detik hingga beberapa menit tergantung pada bahan casting yang dipilih. Dalam hal ini kami mengguanakan logam pewter untuk bahan bakunya. Gambar mesin casting kami sajikan dalam gambar berikut ini.

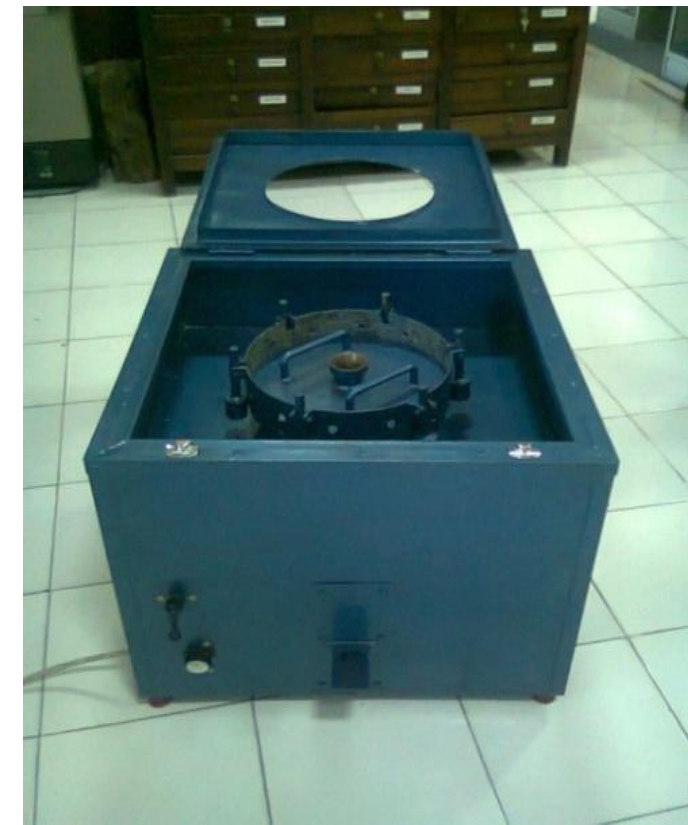

Gambar 3. Mesin Casting

\section{Vulcanizer}

Vulcanizer adalah alat untuk memanaskan karet cetakan. Seperti telah disebutkan sebelumnya, vulkanisasi merupakan langkah penting untuk mempersiapkan cetakan silikon rubber untuk produksi spin casting. Vulcanizer terdiri dari dua buah pemanas yang berada di atas dan di bawah (pararel plat) dan dapat digerakkan ke atas dan ke bawah. Mold frame yang berisi karet silicone mentah diletakkan ditengah-tengah sehingga akan ada tekanan. Proses vulkanisasi terjadi karena adanya plat panas dan tekanan pada mold frame selama beberapa waktu tertentu (tergantung dari jenis karet dan tebalnya) sehingga karet silicone menjadi keras/matang. 


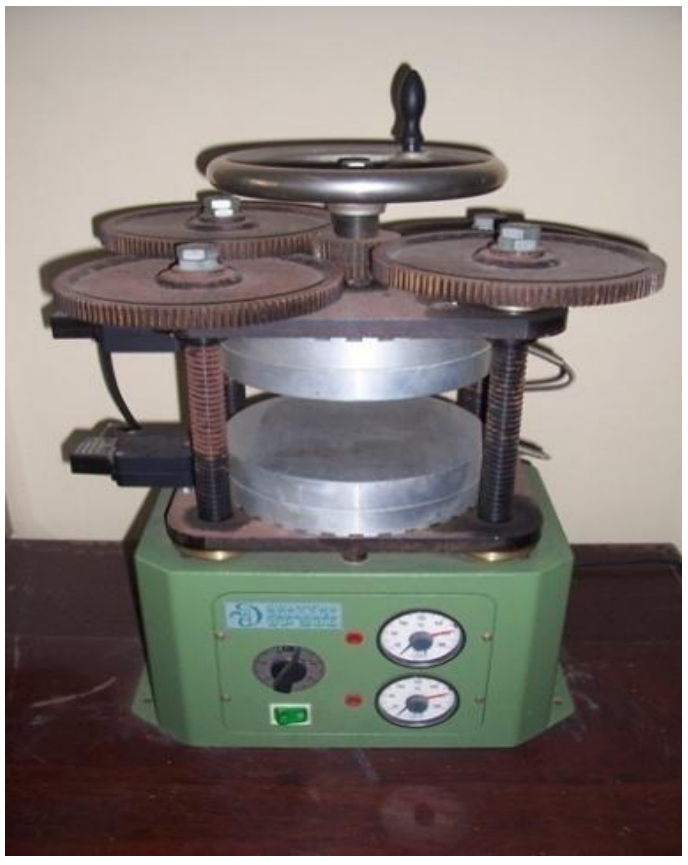

Gambar 4. Mesin Vulcanizer

\section{Tungku kompor gas}

Tungku kompor gas adalah alat untuk mencairkan logam pewter. Karena pada saat proses pengecoran, pewter harus dipanaskan dan dalam keadaan cair. Karena pewter memiliki melting point rendah $\left(231.93^{\circ} \mathrm{C}\right)$ maka cukup dipanaskan diatas kompor yang menyala.

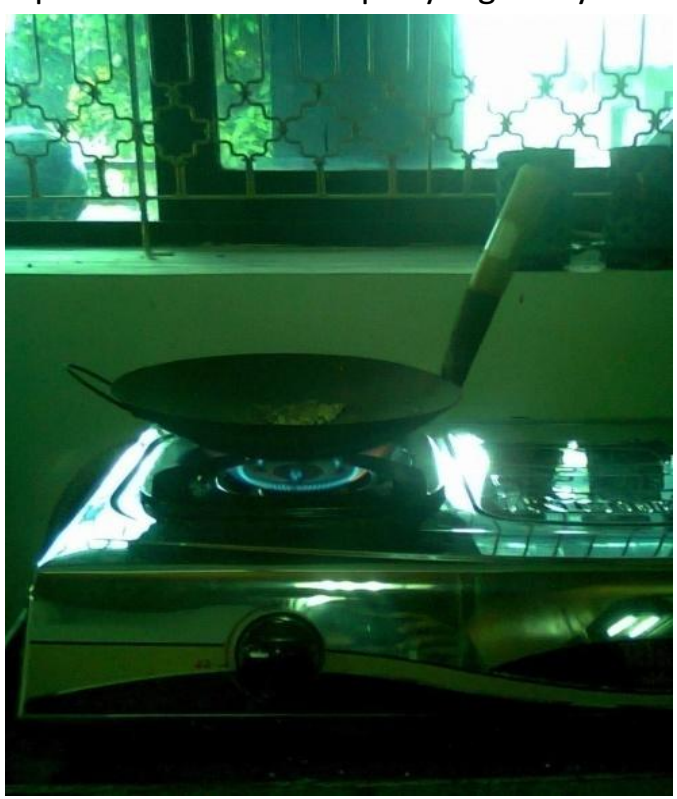

Gambar 5 Wajan pemanas pewter

\section{b. Pengumpulan data dan informasi}

Pengumpulan data dan informasi dilakukan dengan tujuan untuk mendapatkan.informasi atau data melakukan mesin casting yang sudah ada maupun studi literatur dan survey. Studi lapangan dilakukan dengan kunjungan ke lapangan yaitu ke perajin pewter di Kotagede dan kunjungan ke perajin pewter di Pangkalpinang.

\section{c. Prosedur kerja}

Metode penelitian diawali dengan mendefinisikan masalah beserta batasannya, dalam hal ini masalah yang timbul adalah proses produksi yang masih menggunakan teknologi manual, sehingga kecepatan produksi yang rendah. Desain mesin casting yang tepat guna untuk perajin pewter, dengan berdasarkan desain alat yang terdahulu didesain ulang untuk dihasilkan mesin yang dapat bekerja secara optimal. Melakukan kajian literature atas masalah tersebut, tujuannya untuk mengetahui sumber-sumber ilmiah yang berkaitan dengan perancangan desain alat yang sesuai untuk perajin pewter. Sumbersumber yang dikaji berasal dari penelitianpenelitian yang yang sudah dilakukan sebelumnya.

Pengembangan konsep mesin casting untuk perajin pewter dilakukan dengan mengembangkan desain mesin casting yang dilakukan pada penelitian sebelumnya. Kekurangan yang terdapat pada penelitian sebelumnya menjadi dasar kajian untuk meminimalkan kekurangan tersebut. Kajian tersebut menghasilkan komponen/part list penyusun mesin casting yang dapat bekerja lebih maksimal. 
Bahan penelitian pembuatan mesin casting terdiri dari bahan baku alat dan bahan untuk melakukan pengujian mesin. Bahan baku untuk pembuatan mesin casting berupa motor DC $24 \mathrm{~V}$, plat besi, besi siku, regulator kecepatan putaran, poros besi, pully, belt, mur baut dan bahan pendukung lainnya. Bahan untuk pengujian mesin berupa pewter, RTV Silicone, silicone rubber, kompor listrik dan perangkatnya, wajan besi, alat penuang logam, tang kecil, talk/powder dan lainlain.

Pemilihan bahan baku pembuatan mesin casting disesuaikan dengan kemampuan financial perajin pewter dan pengoperasian alat dibuat sederhana agar perajin mudah menggunakannya.

Secara umum perencanaan pembuatan mesin casting dilakukan dengan urutan rencana kerja yang dapat ditampilkan dalam flow chart sebagai berikut :

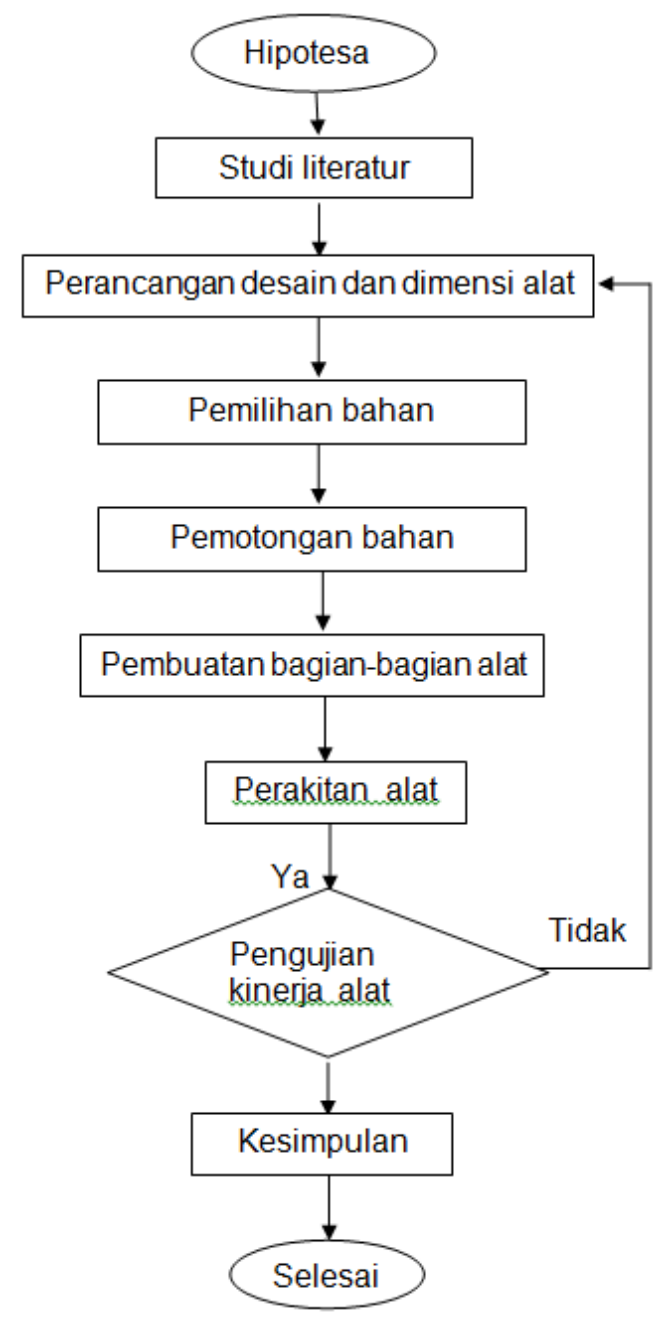

HASIL DAN PEMBAHASAN

A. PEMBUATAN MESIN

Setelah pembuatan desain selesai, langkah selanjutnya adalah pembuatan mesin. Dimulai dengan perakitan mesin dan pembuatan casing mesin. Klasifikasi Mesin adalah sebagai berikut:

- Motor listrik

$\mathrm{Hp}=250$ Watt

$\mathrm{N} \quad=360 \mathrm{rpm}$

$\mathrm{V} \quad=24$ volt $\mathrm{DC}$

- Regulator kecepatan putar

Vinput $=220 \mathrm{AC}$

Voutput $=24 \mathrm{DC}$ 
Arah putaran = CW (Searah jarum jam) atau CCW (Berlawanan jarum jam)

Sedangkan untuk ukuran casing mesin dengan mempertimbangkan dan mengedepankan segi ergonomi (kenyamanan) untuk posisi operator duduk yaitu sekitar $50 \mathrm{~cm}$ sehingga operator dalam mengerjakan pengecoran merasa nyaman dan tidak cepat lelah dan berat 37 kg.agar mudah untuk dipindahkan. Dimensi atau ukuran mesin casting ini adalah $50 \mathrm{~cm}$ $x 50 \mathrm{~cm} \times 50 \mathrm{~cm}$ sehingga menjadikan dimensi ini nyaman digunakan untuk produksi. Penggunaan motor listrik DC 24 Volt dengan tujuan jika listrik mati maka bisa menggunakan sumber listrik alternative yaitu accu 12 volt sebanyak 2 buah. Untuk meneruskan tenaga dari motor digunakan pulley dan belt. Pengunci cetakan karet menggunakan bandul tuas yang bekerja dengan gaya sentripetal. Pengatur kecepatan menggunakan regulator, karena untuk desain tebal menggunakan kecepatan yang rendah, sedangkan desain yang tipis menggunakan kecepatan yang tinggi dan untuk mempercepat penghentikan putaran motor menggunakan rem. Dudukan tempat muolding dibuat dengan ukuran diameter $29 \mathrm{~cm}$ bertujuan agar ukuran moulding dapat bervariasi. Gaya sentripetal menyebabkan terjadinya efek getaran pada alat, untuk meredam efek getaran tersebut digunakan sepatu plastik pada setiap sudut kaki.

Kecepatan produksi diukur berdasarkan siklus sekali proses pencetakan meliputi persiapan karet, penuangan, pendinginan dan pengeluaran produk, dibutuhkan waktu sekitar 2 menit. Jumlah produk dalam cetakan tergantung dari besar kecilnya produk. Untuk gantungan kunci, jumlah produk dalam satu cetakan sekitar $6-8$ buah. Dengan efisiensi keberhasilan pencetakan sebesar $90 \%$ (artinya setiap kali proses, ada 10\% produk yang di reject). Maka perhitungan produksi dalam 5 jam operasi, dengan asumsi jumlah produk setiap kali cetak ada 6 buah:

$$
\begin{gathered}
=5 \text { jam } \times 60 \text { menit } \times 6 \text { produk } \times 90 \% \\
=810 \text { produt }
\end{gathered}
$$

Jika dibandingkan dengan system manual, produk yang dihasilkan dalam sekali cetak hanya 1 buah. Dengan waktu cetak yang sama yaitu 2 menit/proses. Dan tingkat efisiensi yang sama yaitu $90 \%$. Maka perhitungan kapasitas produksi 5 jam operasi sebesar :

$$
\begin{gathered}
=5 \text { jam } \times 60 \text { menit } \times 1 \text { produk } \times 90 \% \\
=135 \text { menit } \\
=13 \text { roduk }
\end{gathered}
$$

Jadi berdasarkan hasil uji coba yang dilakukan dapat disimpulkan bahwa kapasitas produksi dari masinal bisa lebih cepat 6 kali lipat (tergantung dari jumlah produk dalam cetakan). Selain itu kualitas produknya juga lebih bagus jika dibandingkan dengan proses manual, karena tenaga yang dikenakan pada saat pencetakan lebih besar.

\section{Keunggulan mesin casting ini adalah:}

1. Dimensi atau ukuran mesin casting ini adalah $50 \mathrm{~cm} \times 50 \mathrm{~cm} \times 50 \mathrm{~cm}$ sehingga menjadikan dimensi ini nyaman digunakan untuk produksi (segi ergonomi)

2. Penggunaan motor listrik DC 24 Volt dengan tujuan jika listrik mati maka 
bisa menggunakan sumber listrik alternative yaitu accu 12 volt sebanyak 2 buah.

3. Pengatur kecepatan menggunakan regulator, yaitu untuk mengatur kecepatan untuk desain yang tebal dan tipis. karena untuk desain tebal menggunakan kecepatan yang rendah, sedangkan desain yang tipis menggunakan kecepatan yang tinggi

4. Menggunakan rem untuk mempercepat penghentikan putaran motor.

5. Dudukan tempat muolding dibuat dengan ukuran diameter $29 \mathrm{~cm}$ bertujuan agar ukuran moulding dapat bervariasi.

6. Mempunyai dua arah putaran (searah dan berlawanan jarum jam)

\section{Perhitungan Tekno Ekonomi}

Break Even Point (BEP) adalah titik dimana Entity/company/business dalam keadaan belum memperoleh keuntungan, tetapi juga sudah tidak merugi. Dan untuk menghitung BEP ada yang harus diketahui dahulu yaitu biaya tetap (fixed cost) dan biaya tidak tetap (variable cost).

Biaya tetap (Total fixed cost)

Tabel 2 Biaya tetap (Total fixed cost)

\begin{tabular}{|c|l|lr|}
\hline No & \multicolumn{2}{|c|}{ Peralatan } & \multicolumn{2}{c|}{ Harga (Rp) } \\
\hline 1 & Mesin Casting & $\mathrm{Rp}$ & 10.000 .000 \\
\hline 2 & Kompor Gas dan & $\mathrm{Rp}$ & 250.000 \\
& Tabung Gas & & \\
\hline 3 & Wajan & $\mathrm{Rp}$ & 50.000 \\
\hline 4 & Kikir & $\mathrm{Rp}$ & 150.000 \\
\hline 5 & Mesin Polish & $\mathrm{Rp}$ & 200.000 \\
\hline 6 & Alat Penuang & $\mathrm{Rp}$ & 20.000 \\
\hline 7 & Meja Kerja & $\mathrm{Rp}$ & 500.000 \\
\hline 8 & Vulcanizer & $\mathrm{Rp}$ & 3.000 .000 \\
\hline & Jumlah & $\mathrm{Rp}$ & $\mathbf{1 4 . 1 7 0 . 0 0 0}$ \\
\hline
\end{tabular}

Untuk menghitung biaya tidak tetap tergantung seberapa banyak yang akan kita produksi. Jika diasumsikan produk yang kita buat adalah gantungan kunci dengan bahan baku pewter $1 \mathrm{~kg}$ dan berat produk 15 gram. Efisiensi bahan sebesar $90 \%$, artinya dalam proses pembuatan produk akan ada penyusutan sebanyak $10 \% \mathrm{x}$ 1000 gram. Berarti pewter yang jadi produk sebanyak 900 gram sehingga dengan bahan yang ada dapat diproduksi 900 gram : 15 gram $=60$ buah.

\section{A.Biaya Bahan Baku}

Tabel 3. Biaya bahan baku

\begin{tabular}{|c|l|cr|}
\hline No & \multicolumn{2}{|c|}{ Unit } & \multicolumn{2}{c|}{ Biaya (Rp) } \\
\hline 1 & 1 Master Gantungan & $\mathrm{Rp}$ & 25.000 \\
Kunci & Rp & 350.000 \\
\hline 2 & 1 Karet Silicone & $\mathrm{Rp}$ & 270.000 \\
\hline 3 & 1 kg Pewter & $\mathrm{Rp}$ & 12.000 \\
\hline 4 & Amplas & $\mathrm{Rp}$ & 20.000 \\
\hline 5 & Gantungan kunci & $\mathrm{Rp}$ & 16.000 \\
\hline 6 & Gas & $\mathrm{Rp}$ & $\mathbf{6 9 3 . 0 0 0}$ \\
\hline & Jumlah & \multicolumn{3}{|c}{} \\
\hline
\end{tabular}

B.Biaya Tenaga Kerja

Tabel 4. Biaya tenaga kerja

\begin{tabular}{|c|lc|cc|}
\hline No & \multicolumn{2}{|c|}{ Kegiatan } & \multicolumn{2}{c|}{ Biaya (Rp) } \\
\hline 1 & $\begin{array}{l}\text { Penyiapan } \\
\text { Cetakan }\end{array}$ & $\mathrm{Rp}$ & 10.000 \\
\hline 2 & Pencetakan & $\mathrm{Rp}$ & 20.000 \\
\hline 3 & Finishing & $\mathrm{Rp}$ & 60.000 \\
\hline 4 & Perakitan & $\mathrm{Rp}$ & 10.000 \\
\hline & Jumlah & $\mathrm{Rp}$ & 100.000 \\
\hline
\end{tabular}

Variable cost adalah segala biaya untuk memproduksi barang.

Total Biaya tidak tetap (Variable Cost) $\mathrm{Rp}$ $693.000+\operatorname{Rp} 100.000=\operatorname{Rp} 793.000$ 
Variable Cost per unit

$793.000: 60$

$=\operatorname{Rp} 13.216$

Margin keuntungan ditentukan sebesar 30 \% maka didapatkan harga jual produk sebesar Rp $13.216+\operatorname{Rp} 3966=\operatorname{Rp} 17.182$ Rp 17.000

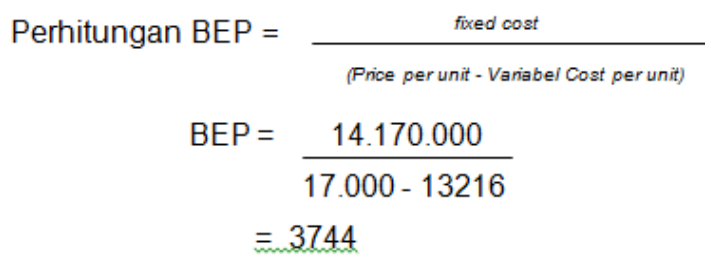

Untuk mencapai BEP perusahaan harus memproduksi sebanyak 3744 buah gantungan kunci selama:

Jika dalam waktu 1 hari dapat enghasilkan 60 buah produk (cetak + finishing) 1 minggu ( 6 hari) menghasilkan 360 buah produk.

BEP : Jumlah Produk 1 minggu

$3744: 360=10.4$ minggu.

$$
=11 \text { minggu }
$$

$11 \times 6$ hari $=66$ hari

\section{KESIMPULAN DAN SARAN}

\section{KESIMPULAN}

Teknologi casting dengan mesin ini dapat mempercepat proses sebesar 6 kali lipat (tergantung dari jumlah produk dalam karet cetakan) jika dibandingkan dengan manual, yang hanya ada satu buah produk dalam satu kali cetakan.

Dengan teknologi mesin casting dapat meningkatkan kualitas produksi untuk desain yang rumit, tipis dan runcing dengan hasil produksi yang maksimal, karena tenaga yang digunakan untuk mencetak lebih besar dari tenaga manual yang hanya menggunakan tenaga gravitasi.

\begin{abstract}
Mesin casting yang dirancang menggunakan motor listrik DC yang bertegangan relatif kecil jadi bisa menggunakan accu sebagai alternatif pengganti listrik untuk pengoperasian mesin ini, sehingga mesin ini cocok digunakan oleh perajin pewter, khususnya perajin pewter yang sering terkena giliran pemadaman listrik.
\end{abstract}

\section{SARAN}

Untuk mengetahui lebih jauh unjuk kerja mesin casting perlu dilakukan rekayasa lebih lanjut dengan melengkapi dengan pembaca kecepatan putar. Dan percobaan dengan variabel ketebalan dan dimensi produk yang lain.

\section{DAFTAR PUSTAKA}

Suwardo, A.Sri Bandono, Pengetahuan Teknologi Kerajinan Logam 2, (Direktorat Pendididkan Menengah Kejuruan Departemen Pendidikan dan Kebudayaan, 1980)

Sularso., Dasar Perencanaan Dan Pemilihan Elemen Mesin, PT Pradnya Paramita, Jakarta. 1980 Tata Sudia, Tehnik Pengecoran Logam, (Jakarta : PT. Pradnya Paramita, 1986).

Fiqrul Islami, Analisis Penerapan Casting Centrifugal pada Produksi Perhiasan Perak di BBKB, Universitas Sarjana Wiyata Tamansiswa, 2008.

http://www.en.wikipedia.org/wiki/Pattern

http://www.en.wikipedia.org/wiki/Tin

http//www.en.wikipedia.org/Spin_Casting 